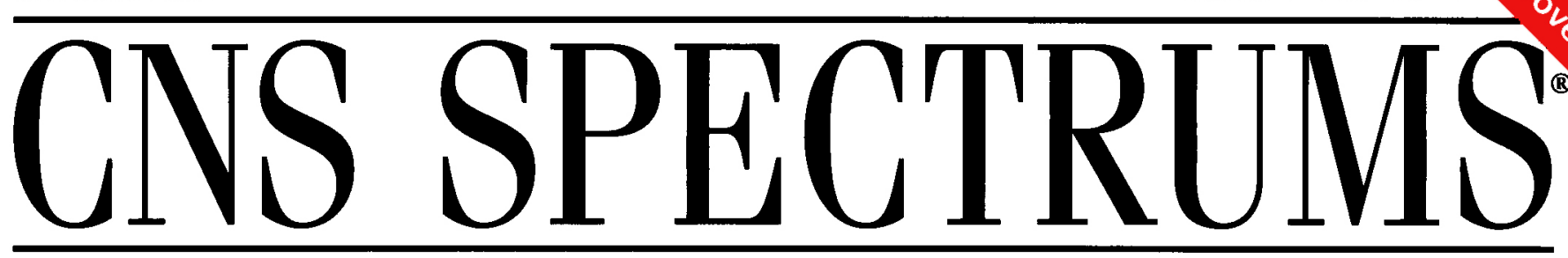

The International Journal of Neuropsychiatric Medicine

\title{
Investigating Neuropsychiatric Disorders
}

\author{
ORIGINAL RESEARCH \\ Global Benefit-risk Evaluation of \\ Antidepressant Action: Comparison of \\ Pooled Data for Venlafaxine, SSRIs, and Placebo \\ R. Entsuab and B. Goa \\ REVIEW \\ Neurocognitive Manifestions of \\ Human Immunodeficiency Virus \\ R.H. Paul, R.A. Coben, and R.A. Stern \\ REVIEW \\ Literary Factitious Epilepsy Syndrome \\ J.M. Jones \\ REVIEW \\ Substance $P$ and \\ Human Immunodeficiency Virus Infection: \\ Psychoneuroimmunology \\ W-Z. Ho, D.L. Evans, and S.D. Douglas \\ CASE STUDY \\ An Unusual Case of \\ Motor and Vocal Tics With \\ Obsessive-Compulsive Symptoms in a \\ Young Adult With Behçet's Syndrome \\ C. Budman and A. Sarcevic \\ THE NEUROLOGY OF BEHAVIOR \\ William James and the Varieties of \\ Religious Experience \\ M. Trimble

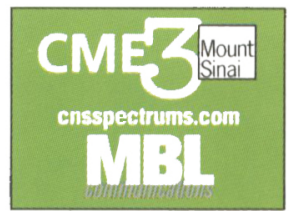




\section{January}

\begin{tabular}{|c|c|c|c|c|c|c|}
\hline Sunday & Monday & Tuesday & Wednesday & Thursday & Friday & Saturday \\
\hline & & & $\begin{array}{l}1(-31) \\
\text { Baylor College } \\
\text { Medicine } \\
\text { Evaluation of t } \\
\text { With the First } \\
\text { Houston } \\
\text { Contact: } \\
\text { Tel: } 711 \text {-798-88 } \\
\text { cme@bcm.tmc }\end{array}$ & 2 & 3 & 4 \\
\hline 5 & 6 & 7 & 8 & 9 & 10 & $11(-12$ \\
\hline
\end{tabular}

\begin{tabular}{|c|c|c|c|c|c|}
\hline \multirow[t]{2}{*}{12} & 13 & 14 & $16(-17)$ & $17(-19)$ & 18 \\
\hline & & $\begin{array}{l}\text { Southern Illinois } \\
\text { University Medical } \\
\text { School } \\
\text { Neuroradiology } \\
\text { Conference } \\
\text { Springfield, IL } \\
\text { Contact: } \\
\text { Tel: 217-545-4413 } \\
\text { bshelow@siumed.edu }\end{array}$ & $\begin{array}{l}\text { L'Institut Pasteur } \\
\text { Depression: Emerging } \\
\text { Research and } \\
\text { Treatment Approach } \\
\text { Paris } \\
\text { Contact: } \\
\text { Tel: 33-0-140-613-405 } \\
\text { euroconf@pasteurfr. }\end{array}$ & $\begin{array}{l}\text { Annual Meeting of the } \\
\text { California Association } \\
\text { of Neurological } \\
\text { Surgeons } \\
\text { Newport Beach, CA } \\
\text { Contact: } \\
\text { Tel: } 916-457-2267 \\
\text { jttns@aol.com }\end{array}$ & \\
\hline
\end{tabular}

\begin{tabular}{|c|c|c|c|c|}
\hline 26 & 27 & $\begin{array}{l}28 \text { (-31) } \\
\text { Annual Meeting of the } \\
\text { Australian } \\
\text { Neuroscience Society } \\
\text { Adelaide, Australia } \\
\text { Contact: } \\
\text { Tel:61-882-044-263 } \\
\text { judy.morris@ } \\
\text { flinders.edu.au }\end{array}$ & $\begin{array}{l}29 \text { (-Feb 1) } 30 \\
\text { Congress of the Neuro- } \\
\text { logical Association of } \\
\text { South Africa } \\
\text { Cape Town, South Africa } \\
\text { Contact: } \\
\text { selliott@ } \\
\text { cure.uct.ac.za }\end{array}$ & $\begin{array}{l}31 \text { (-Feb 7) } \\
\text { University of Utah } \\
\text { Health Sciences Center } \\
\text { Winter Neurosurgical } \\
\text { Conference } \\
\text { Snowbird, UT } \\
\text { Contact: } \\
\text { Tel: 801-581-6554 } \\
\text { lanette.dunbar@ } \\
\text { hsc.utah.edu }\end{array}$ \\
\hline
\end{tabular}




\section{0-Day Planner}

\section{MEETINGS}

\section{February}

\begin{tabular}{|c|c|c|c|c|c|c|}
\hline Sunday & Monday & Tuesday & Wednesday & Thursday & Friday & Saturday \\
\hline & & & & & & $1(-28)$ \\
\hline & & & & & & $\begin{array}{l}\text { Baylor College } \\
\text { of Medicine } \\
\text { Evaluation of the Child } \\
\text { With the First Seizure } \\
\text { Houston } \\
\text { Contact: } \\
\text { Tel: } 713-798-8237 \\
\text { cme@bcm.tmc.edu }\end{array}$ \\
\hline 2 & $3(-7)$ & 4 & $5(-8)$ & 6 & 7 & 8 \\
\hline & $\begin{array}{l}\text { Harvard } \\
\text { Medical School } \\
\text { Mini-Fellowship in } \\
\text { Transcranial Magnetic } \\
\text { Stimulation } \\
\text { Boston } \\
\text { Contact: } \\
\text { Tel: 617-384-8600 } \\
\text { hms-cme@ } \\
\text { hms.harvard.edu }\end{array}$ & & $\begin{array}{l}\text { Annual Meeting } \\
\text { of the International } \\
\text { Neuropsychological } \\
\text { Society } \\
\text { Honolulu } \\
\text { Contact: } \\
\text { Tel:614-263-4200 } \\
\text { osu_ins@ } \\
\text { postbox.acs.ohio- } \\
\text { state.edu }\end{array}$ & & & $\begin{array}{l}\text { Johns Hopkins } \\
\text { Medical Institutions } \\
\text { Parkinson's Disease } \\
\text { and Related } \\
\text { Movement Disorders } \\
\text { in Primary Care } \\
\text { Baltimore } \\
\text { Contact: } \\
\text { Tel: 410-955-2959 } \\
\text { cmenet@jhmi.edu }\end{array}$ \\
\hline 9 & 10 & 11 & $12(-14)$ & 13 & 14 & 15 \\
\hline & & & $\begin{array}{l}\text { 8th International } \\
\text { Conference on Mental } \\
\text { Retardation and Other } \\
\text { Developmental } \\
\text { Disabilitites: Research } \\
\text { to Practice } \\
\text { Kauai, HI } \\
\text { Contact: } \\
\text { Tel: 905-890-1010 } \\
\text { cperras@cgocablle.net }\end{array}$ & $\begin{array}{l}\text { 28th International } \\
\text { Stroke Conference } \\
\text { Phoenix } \\
\text { Contact: } \\
\text { Tel: 214-706-1100 } \\
\text { Fax: 214-706-5262 } \\
\end{array}$ & & \\
\hline 16 & 17 & $18(-22)$ & 19 & 20 & 21 & $22(-26)$ \\
\hline & & $\begin{array}{l}\text { Inaugural Meeting of the } \\
\text { European Chapter of the } \\
\text { International Society for } \\
\text { Neuronal Regulation } \\
\text { Undine, Italy } \\
\text { Contact: } \\
\text { Tel: 351-916-305-575 } \\
\text { belling@clix.pt }\end{array}$ & & & & $\begin{array}{l}\text { 2nd International } \\
\text { Meeting on Steroids and } \\
\text { Nervous System } \\
\text { Torino, Italy } \\
\text { Contact: } \\
\text { Tel: 39-0-116-707-732 } \\
\text { giancarlo.panzica@ } \\
\text { unito.it }\end{array}$ \\
\hline 23 & 24 & 25 & $26(-28)$ & 27 & 28 & \\
\hline & & & $\begin{array}{l}\text { 4th Latinamerican } \\
\text { Congress of Neuropsy- } \\
\text { chopharmacology } \\
\text { Cartagena, Colombia } \\
\text { Contact: } \\
\text { Tel: } 571-215-0010 \\
\text { clanp2003@ } \\
\text { yahoo.com }\end{array}$ & & & \\
\hline
\end{tabular}




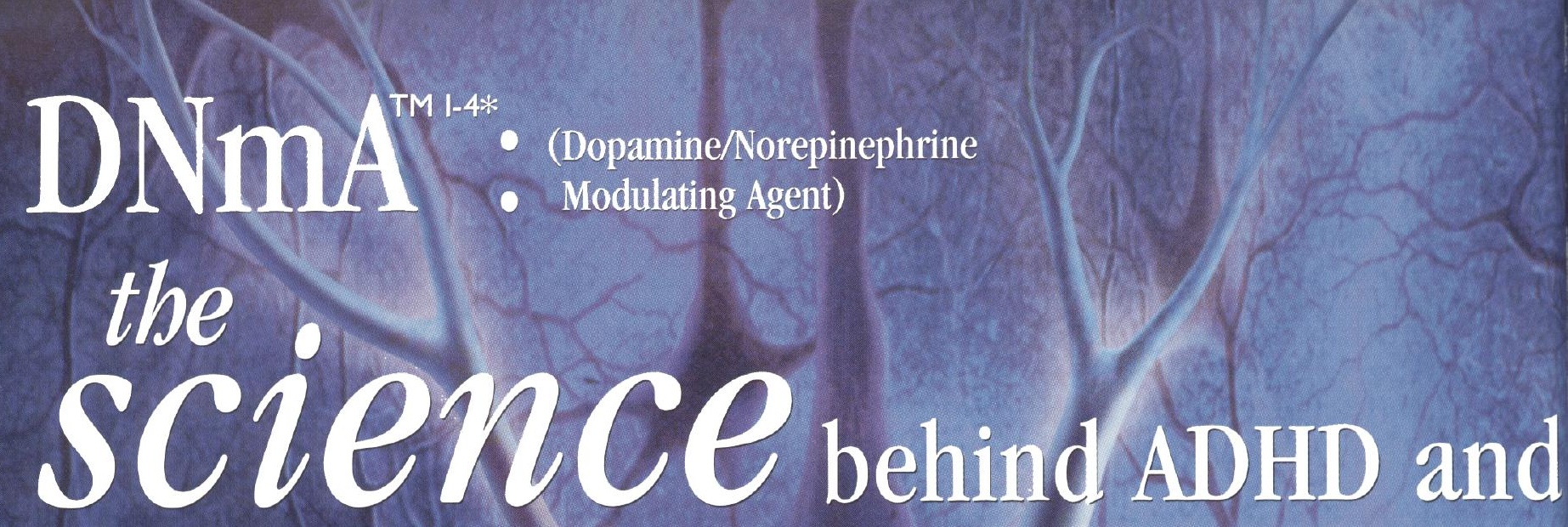

\section{NEW Strengths $5 \mathrm{mg}, 15 \mathrm{mg}$, and $25 \mathrm{mg}$ Capsules} Provide Even More Flexibility

ADDERALL XR was generally well tolerated in clinical trials of pediatric patients. The most comm adverse events include loss of appetite, insomnia, abdominal pain, and emotional lability. As with other psychostimulants indicated for ADHD, there is a potential for exacerbating motor and phonic tics and Tourette's syndrome. A side effect seen with the amphetamine class is psychosis. Administration of amphetamine may exacerbate symptoms of behavior disturbances and thought disorder in psychotic patients. ADDERALL XR is contraindicated in patients with symptomatic cardiovascular disease, moderate to severe hypertension, hyperthyroidism and glaucoma, known hypersensitivity or idiosyncrasy to sympathomimetic amines, agitated states, history of drug abuse, or within 14 days of administration of a MAO inhibitor. The possibility of growth suppression warrants monitoring of patients receiving long-term therapy. Prolonged use of amphetamines may lead to drug dependence. ADDERALL XR should be prescribed with close physician supervision as part of a multimodal treatment program for ADHD.

References: I. Kuczenski R, Segal DS. Neurochemistry of amphetamine. In: Cho AK, Segal DS, eds. Amphetamine and its Analogs: Psychopharmocology, Toxicologg, and Abuse. San Diego, Calif: Academic Press; I994:81-II3. 2. Wilens TE, Spencer T). Pharmacology of amphetamines. In: Tarter RE, Ammerman RT, Ott P], eds. Handbook of SubstanceAbuse: Neurobehovioral Pharmacology. New York, NY: Plenum Press; 1998:50I-5I3. 3. Grace AA. Psychostimulant actions on dopamine and limbic system function: relevance to the pathophysiology and treatment of ADHD. In: Solanto MV, Arnsten AFT, Castellanos FX, eds. Stimulant Drugs and ADHD: Basic and Clinical Neuroscience. New York, NY: Oxford University Press; 200I:

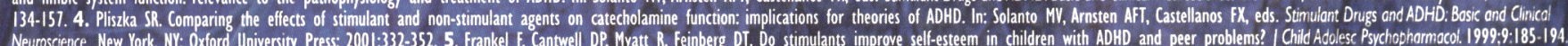

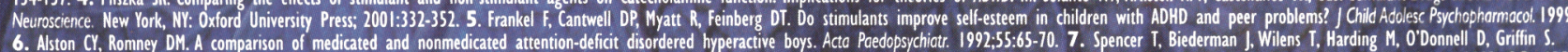
6. Alston CY, Romney DM. A comparison of medicated and nonmedicated attention-deficit disordered hyperactive boys. Acto Pcedopsychiatr. 1992;55:65-70. 7. Spencer T, Biederman J, Wilens I, Harding M, O Donnell O, Grilin S.
Pharmacotherapy of attention-deficit hyperactivity disorder across the life cycle. AmA Acod Child Adolesc Psychiatry. 1996;35:409-432. 8. ADDERALL package insert, Shire US Inc., 2000. 9. Data on file, Shire US Inc., 2002. I0. ADDERALL XR package insert, Shire US Inc., 2002. II. Biederman J. Lopez FA, Boellher SW, Chandler MC. A randomized, double-blind, placebo-controlled, parallel-group study of SLI38I [ADDERALL XR] in children with attention deficit hyperactivity disorder. Pediatrics. In press. 12. Mecracken JT, Biederman J, Greenhill L, et al. Analog classroom assessment of SLI38I for the treatment of ADHD. Poster presented at: 47th Annual Meeting of the American Academy of Child and Adolescent Psychiatry; October 26, 2000; New York, NY. I3. Ambrosini PJ, Lopez FA, Chandler MC, Tulloch SJ, Michaels MA. An open-label community assessment trial of Adderall XR in pediatric ADHD. Poster presented at: I55th Annual Meeting of the American Psychiatric Association; May 22, 2002; Philadelphia, Pa.

* Mechanism not proven but supported by current scientific hypotheses. 


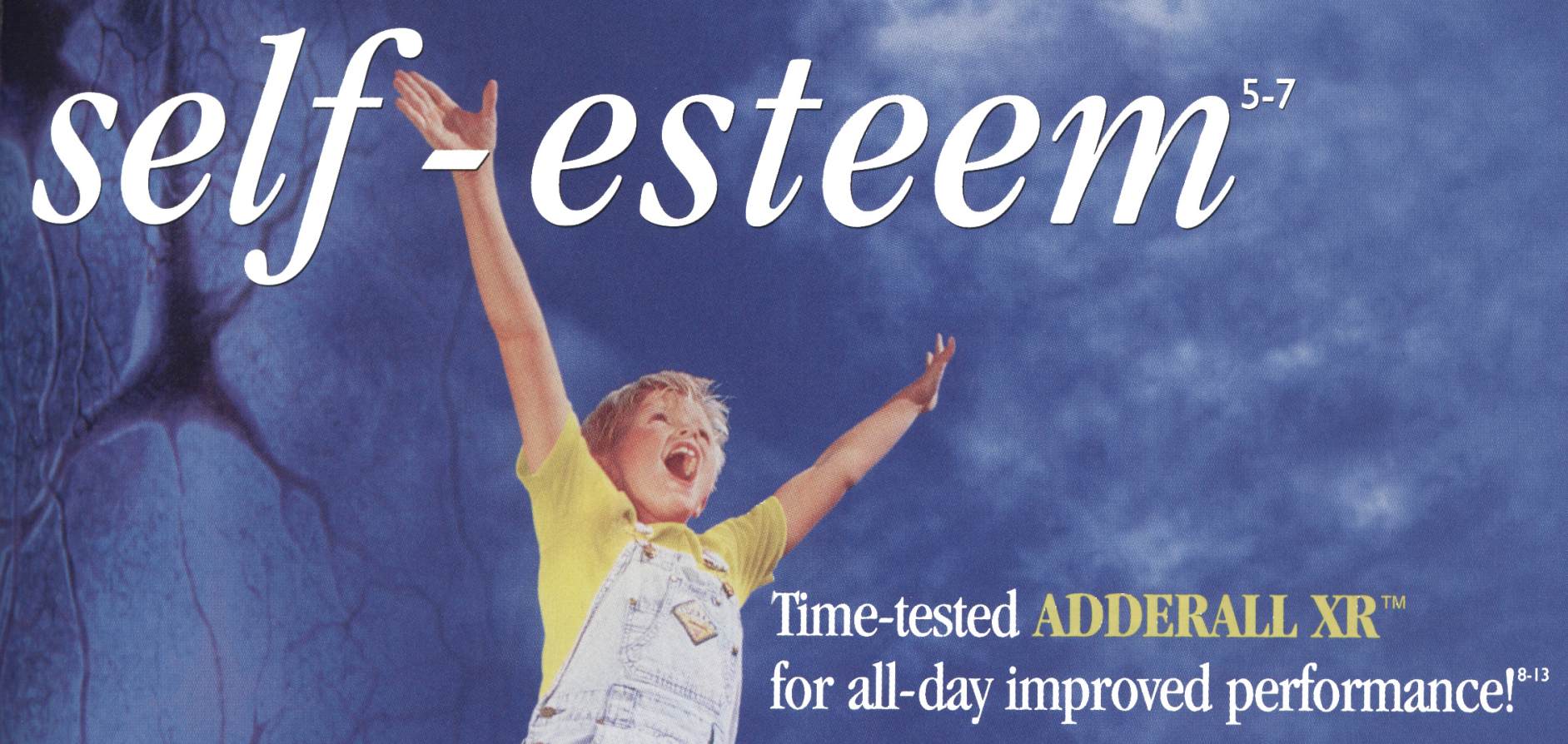

Dopamine (DA) and norepinephrine (NE) are believed to play critical roles in the pathology and treatment of ADHD. ${ }^{1.4}$

ADDERALL XR is thought to increase the levels of both DA and NE in the synapse. ${ }^{1.4}$

\section{ADDERALL XR provides unparalleled dosing}

flexibility with significant all-day improvement in ${ }^{9-12}$ :

- Attention

- Behavior

- Academic Performance

Make patient-friendly ADDERAUL XR your ADHD treatment option of choice!

Please see references to left and a brief summary of prescribing information on adjacent page.
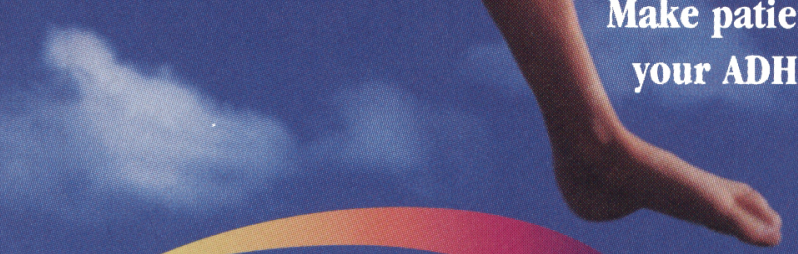

$5 \mathrm{mg}, 10 \mathrm{mg}, 15 \mathrm{mg}, 20 \mathrm{mg}, 25 \mathrm{mg}, 30 \mathrm{mg}$ CAPSUL (Mixed Salts of a Single-Entity Amphetamine Product) Dextroamphetamine Sulfate Dextroamphetamine Saccharate Amphetamine Aspartate Monohydrate Amphetamine Sulfate

Removing obstacles in $\mathrm{ADHD}^{\mathrm{m}}$ 


\section{OnE Dose Dalir}

$5 \mathrm{mg}, 10 \mathrm{mg}, 15 \mathrm{mg}, 20 \mathrm{mg}, 25 \mathrm{mg}, 30 \mathrm{mg}$ CAPSULES (Mixed Salts of a Single-Entity Amphetamine Product)
Dextroamphetamine Sultate Dextroamphetamine Saccharate

BRIEF SUMMARY: Consult the full prescribing information for complete product information. ADDERALL XRTM CAPSULES

CII Rx Only

AMPHETAMINES HAVE A HIGH POTENTIAL FOR ABUSE. ADMINISTRATION OF AMPHETAMINES FOR PROLONGED PERIODS OF TIME MAY LEAD TO DRUG DEPENDENCE. PARTICULAR ATTENTION SHOULD
BE PAID TO THE POSSIBILITY OF SUBJECTS OBTAINING AMPHETAMINES FOR NON-THERAPEUTIC USE BE PAID TO THE POSSIBILITY OF SUBJECTS OBTAINING AMPHETAMINES FOR NON-THERAPEUTIC USE
OR DISTRIBUTION TO OTHERS AND THE DRUGS SHOULD BE PRESCRIBED OR DISPENSED SPARINGLY.

\section{INDICATIONS}

ADDERALL XRTM is indicated for the treatment of Attention Deficit Hyperactivity Disorder (ADHD).

The efficacy of ADDERALL XRTM in the treatment of ADHD was established on the basis of two controlled rials of children aged 6 to 12 who met DSM-IV criteria for ADHD, along with extrapolation from the known efficacy of ADDERALL ${ }^{*}$, the immediate-release formulation of this substance.

\section{CONTRAINDICATIONS}

Advanced arteriosclerosis, symptomatic cardiovascular disease, moderate to severe hypertension hyperthyroidism, known hypersensitivity or idiosyncra

During or within 14 days following the administration of monoamine oxidase inhibitors (hypertensive crises may result).

WARNINGS

Psychosis: Clinical experience suggests that, in psychotic patients, administration of amphetamine may exacerbate symptoms of behavior disturbance and thought disorder.

Long-Term Suppression of Growth: Data are inadequate to determine whether chronic use of stimulants in children, including amphetamine, may be causally associated with suppression of growth. Therefore, growth have their treatment interrupted.

PRECAUTIONS

General: The least amount of amphetamine feasible should be prescribed or dispensed at one time in order to minimize the possibility of overdosage.

Hypertension and other Cardiovascular Conditions: Caution is to be exercised in prescribing amphetamines for patients with even mild hypertension (see CONTRAINDICATIONS). Blood pressure and pulse should be monitored at appropriate intervals in patients taking ADDERALL XR ${ }^{T M}$, especially patients with hypertension.
Tics: Amphetamines have been reported to exacerbate motor and phonic tics and Tourette's syndrome. Therefore, clinical evaluation for tics and Tourette's syndrome in children and their families should precede use of stimulant medications.

Information for Patients: Amphetamines may impair the ability of the patient to engage in potentially hazardous activities such as operating machinery or vehicles; the patient should therefore be cautioned accordingly.

Drug Interactions: Acidifying agents-Gastrointestinal aciditying agents (guanethidine, reserpine, glutamic acid $\mathrm{HCl}$, ascorbic acid, etc.) lower absorption of amphetamines

Urinary acidifying agents - These agents (ammonium chloride, sodium acid phosphate, etc.) increase the concentration of the ionized species of the amphetamine molecule, thereby increasing urinary excretion. Both groups of agents lower blood levels and efficacy of amphetamines.

Adrenergic blockers - Adrenergic blockers are inhibited by amphetamines.

Alkalinizing agents-Gastrointestinal alkalinizing agents (sodium bicarbonate, etc.) increase absorption of amphetamines. Co-administration of ADDERALL XR $\mathrm{R}^{\text {TM }}$ and gastrointestinal alkalinizing agents, such as antacids, should be avoided. Urinary alkalinizing agents (acetazolamide, some thiazides) increase the concentration of the non-ionized species of the amphetamine molecule, thereby decreasing urinary excretion. Both groups of agents increase blood levels and therefore potentiate the actions of amphetamines.

Antidepressants, tricyclic - Amphetamines may enhance the activity of tricyclic antidepressants or sympathomimetic agents; d-amphetamine with desipramine or protriptyline and possibly other tricyclics cause striking and sustained increases in the concentration of d-amphetamine in the brain; cardiovascular effects can be potentiated.

MAO inhibitors-MAOI antidepressants, as well as a metabolite of furazolidone, slow amphetamine metabolism. This slowing potentiates amphetamines, increasing their effect on the release of norepinephrine
and other monoamines from adrenergic nerve endings; this can cause headaches and other signs of and other monoamines from adrenergic nerve endings; this can cause headaches and other signs of
hypertensive crisis. A variety of toxic neurological effects and malignant hyperpyrexia can occur, sometimes hypertensive crisis.
with fatal results.

with fatal results.
Antihistamines-Amphetamines may counteract the sedative effect of antihistamines.

Antihypertensives-Amphetamines may antagonize the hypotensive effects of antihypertensives.

Chlorpromazine-Chlorpromazine blocks dopamine and norepinephrine receptors, thus inhibiting the central stimulant effects of amphetamines, and can be used to treat amphetamine poisonin

Ethosuximide-Amphetamines may delay intestinal absorption of ethosuximide.

Haloperidol-Haloperidol blocks dopamine receptors, thus inhibiting the central stimulant effects of amphetamines.

Lithium carbonate-The anorectic and stimulatory effects of amphetamines may be inhibited by lithium carbonate.

Meperidine-Amphetamines potentiate the analgesic effect of meperidine.

Methenamine therapy-Urinary excretion of amphetamines is increased, and efficacy is reduced, by acidifying agents used in methenamine therapy.

orepinephrine-Amphetamines enhance the adrenergic effect of norepinephrine.

Phenobarbita-Amphetamines may delay intestinal absorption of phenobarbital; co-administration of phenobarbital may produce a synergistic anticonvulsant action.

of phenytoin; $\mathrm{co}$-administration of phenytoin may

Propoxyphene- In cases of propoxyphene overdosage, amphetamine CNS stimulation is potentiated and fatal convulsions can occur.

Veratrum alkaloids-Amphetamines inhibit the hypotensive effect of veratrum alkaloids.

Drug/Laboratory Test Interactions: Amphetamines can cause a significant elevation in plasma corticosteroid levels. This increase is greatest in the evening.

Amphetamines may interfere with urinary steroid determinations.

Carcinogenesis/Mutagenesis and Impairment of Fertility: No evidence of carcinogenicity was found in studies in which d,l-amphetamine (enantiomer ratio of 1:1) was administered to mice and rats in the diet for and female rats. These doses are approximately $2.4,1.5$, and 0.8 times, respectively, the maximum recommended human dose of $30 \mathrm{mg} / \mathrm{day}$ on a $\mathrm{mg} / \mathrm{m}^{2}$ body surface area basis.

recommended human dose of $30 \mathrm{mg} / \mathrm{day}$ on a $\mathrm{mg} / \mathrm{m}^{2}$ body surface area basis.
Amphetamine, in the enantiomer ratio present in $\mathrm{ADDERALL}^{\oplus}$ (immediate-release)( $\mathrm{d}$ - to 1 - ratio of $3: 1$ ), was not clastogenic in the mouse bone marrow micronucleus test in vivo and was negative when tested in the E. coli component of the Ames test in vitro. d, I-Amphetamine ( $1: 1$ enantiomer ratio) has been reported to produce a positive response in the mouse bone marrow micronucleus test, an equivocal response in the Ames produce a positive response in the mouse bone marrow micronucleus test, an equivocal response in the Ames
test, and negative responses in the in vitro sister chromatid exchange and chromosomal aberration assays. Amphetamine, in the enantiomer ratio present in ADDERALL (immediate-release)(d- to l-ratio of 3:1), did not adversely affect fertility or early embryonic development in the rat at doses of up to $20 \mathrm{mg} / \mathrm{kg} / \mathrm{day}$ (approximately 5 times the maximum recommended human dose of $30 \mathrm{mg} /$ day on a $\mathrm{mg} / \mathrm{m}^{2}$ body surface area basis).

Pregnancy: Pregnancy Category C. Amphetamine, in the enantiomer ratio present in ADDERALL ${ }^{\odot}$ (d- to 1-ratio of $3: 1$ ), had no apparent effects on embryofetal morphological development or survival when orally administered to pregnant rats and rabbits throughout the period of organogenesis at doses of up to 6 and $16 \mathrm{mg} / \mathrm{kg} /$ day, respectively. These doses are approximately 1.5 and 8 times, respectively, the maximum recommended human dose of $30 \mathrm{mg} / \mathrm{day}$ on a $\mathrm{mg} / \mathrm{m}^{2}$ body surface area basis. Fetal malformations and death have been reported in mice following parenteral administration of d-amphetamine doses of $50 \mathrm{mg} / \mathrm{kg} / \mathrm{day}$ to pregnant animals. Administration of these doses was also associated with severe maternal toxicity to pregnant animals. Administration of these doses was also associated with severe maternal toxicity. A number of studies in rodents indicate that prenatal or early postnatal exposure to amphetamine (d-or d, I-), Reported behavioral effects include learning and memory deficits, altered locomotor activity, and changes in sexual function.

There are no adequate and well-controlled studies in pregnant women. There has been one report of severe congenital bony deformity, tracheo-esophageal fistula, and anal atresia (vater association) in a baby born to a woman who took dextroamphetamine sulfate with lovastatin during the first trimester of pregnancy. Amphetamines should be used during pregnancy only if the potential benefit justifies the potential risk to the fetus.
Nonteratogenic Effects: Infants born to mothers dependent on amphetamines have an increased risk of premature delivery and low birth weight. Also, these infants may experience symptoms or withdrawal as Usage in Nursing Mothers: Amphe

be advised to refrain from nursing.

Pediatric Use: ADDERALL XR $\mathrm{X}^{\mathrm{TM}}$ is indicated for use in children 6 years of age and older.

Use in Children Under Six Years of Age: Effects of ADDERALL XR ${ }^{T M}$ in 3-5 year olds have not been studied. Lng-term effects of amphetamines in children have not been well established. Amphetamines are not

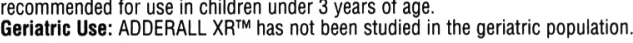

\section{ADVERSE EVENTS}

The premarketing development program for ADDERALL XR $\mathrm{R}^{\mathrm{TM}}$ included exposures in a total of 685 participants in clinical trials (615 patients, 70 healthy adult subjects). These participants received ADDERALL XR ${ }^{T M}$ at daily doses up to $30 \mathrm{mg}$. The 615 patients (ages 6 to 12) were evaluated in two controlled clinical studies, one
open-label clinical study, and one single-dose clinical pharmacology study ( $N=20)$. Safety data on all patients open-label clinical study, and one single-dose clinical pharmacology study ( $N=20)$. Safety data on all patients are included in the discussion that follows. Adverse reactions were assessed by coll
results of physical examinations, vital signs, weights, laboratory analyses, and ECGs.

results of physical examinations, vital signs, weights, laboratory analyses, and ECGs. Adverse events during exposure were obtained primarily by general inquiry and recorded by clinical investigators using terminology of their own choosing. Consequently, it is not possible to provide a meaningful estimate of the proportion of individuals experiencing adverse events without first grouping similar types of events into a smaller number of standardized event categories. In th

The stated frequencies of adverse events represent the proportion of individuals who experienced, at least once, a treatment-emergent adverse event of the type listed.

Adverse events associated with discontinuation of treatment: In two placebo-controlled studies of up to patients discontinued due to adverse events (including 3 patients with loss of appetite, one of whom also reported insomnia) compared to $2.7 \%(7 / 259)$

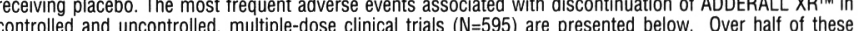
patients were exposed to ADDERALL XR T $^{\text {TM }}$ for 12 months or more

$\begin{array}{ll}\text { Adverse event } & \% \text { of patients discontinuing (N=595) } \\ \text { Anorexia (loss of appetite) } & 2.9 \\ \text { Insomnia } & 1.5 \\ \text { Weight loss } & 1.2 \\ \text { Emotional lability } & 1.0 \\ \text { Depression } & 0.7\end{array}$

Adverse events occurring in a controlled trial: Adverse events reported in a 3-week clinical trial of pediatric patients treated with ADDERALL XR ${ }^{T M}$ or placebo are presented in the table below.

The prescriber should be aware that these figures cannot be used to predict the incidence of adverse events in the course of usual medical practice where patient characteristics and other factors differ from those which prevailed in the clinical trials. Similarly, the cited frequencies cannot be compared with figures obtained from other clinical investigations involving different treatments, uses, and investigators. The cited figures, however, non-drug factors to the adverse event incidence rate in the population studied.

Table 1 Adverse Events Reported by More Than $1 \%$ of Patients Receiving ADDERALL XR ${ }^{\text {TM }}$ with Higher Incidence Than on Placebo in a 584 Patient Clinical Study

\begin{tabular}{|c|c|c|c|}
\hline Body System & Preferred Term & ADDERALL $X^{\mathrm{rm}}(\mathrm{N}=374)$ & Placebo ( $N=210)$ \\
\hline \multirow[t]{6}{*}{ General } & Abdominal Pain (stomachache) & $14 \%$ & $10 \%$ \\
\hline & Accidental Injury & $3 \%$ & $2 \%$ \\
\hline & Asthenia (fatigue) & $2 \%$ & $0 \%$ \\
\hline & Fever & $5 \%$ & $2 \%$ \\
\hline & Infection & $4 \%$ & $2 \%$ \\
\hline & Viral Infection & $2 \%$ & $0 \%$ \\
\hline \multirow[t]{5}{*}{ Digestive System } & Loss of Appetite & $22 \%$ & $2 \%$ \\
\hline & Diarrhea & $2 \%$ & $1 \%$ \\
\hline & Dyspepsia & $2 \%$ & $1 \%$ \\
\hline & Nausea & $5 \%$ & $3 \%$ \\
\hline & Vomiting & $7 \%$ & $4 \%$ \\
\hline \multirow[t]{4}{*}{ Nervous System } & Dizziness & $2 \%$ & $0 \%$ \\
\hline & Emotional Lability & $9 \%$ & $2 \%$ \\
\hline & Insomnia & $17 \%$ & $2 \%$ \\
\hline & Nervousness & $6 \%$ & $2 \%$ \\
\hline Metabolic/Nutritional & Weight Loss & $4 \%$ & $0 \%$ \\
\hline
\end{tabular}

The following adverse reactions have been associated with amphetamine use:

Cardiovascular: Palpitations, tachycardia, elevation of blood pressure. There have been isolated reports of cardiomyopathy associated with chronic amphetamine use.

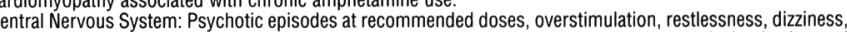
insomnia, euphoria, dyskinesia, dysphoria, tremor, headache, exacerbation of motor and phonic tics and Tourette's syndrome.

Gastrointestinal: Dryness of the mouth, unpleasant taste, diarrhea, constipation, other gastrointestinal disturbances. Anorexia and weight loss may occur as undesirable effects.

Allergic: Urticaria.

\section{DRUG ABUSE AND DEPENDENCE}

ADDERALL XRTM is a Schedule II controlled substance. social disability have occurred. There are reports of patients who have increased the dosage to many times that recommended. Abrupt cessation following prolonged high dosage administration results in extreme fatigue and mental depression; changes are also noted on the sleep EEG. Manifestations of chronic intoxication with amphetamines may include severe dermatoses, marked insomnia, irritability, hyperactivity, and personality changes. The most severe manifestation of chronic intoxication is psychosis, often clinically indistinguishable from schizophrenia.

\section{OVERDOSAGE}

Individual patient response to amphetamines varies widely. Toxic symptoms may occur idiosyncratically at ow doses.

Symptoms: Manifestations of acute overdosage with amphetamines include restlessness, tremor hyperreflexia, rapid respiration, confusion, assaultiveness, hallucinations, panic states, hyperpyrexia and rhabdomyolysis. Fatigue and depression usually follow the central nervous system stimulation. Cardiovascular effects include arrhythmias, hypertension or hypotension and circulatory collapse. Gastrointestinal symptoms
include nausea, vomiting, diarrhea, and abdominal cramps. Fatal poisoning is usually preceded by convulsions include nausea. Treatment: Consult with a Certified Poison Control Center for up-to-date guidance and advice. Management of acute amphetamine intoxication is largely symptomatic and includes gastric lavage, administration of activated charcoal, administration of a cathartic and sedation. Experience with hemodialysis or peritoneal dialysis is inadequate to permit recommendation in this regard. Acidification of the urine increases amphetamine excretion, but is believed to increase risk of acute renal failure if myoglobinuria is present. If acute severe sugested. However, a gradual drop in blood pressure will usually result when sufficient sedation has been achieved. Chlorpromazine antagonizes the central stimulant effects of amphetamines and can be used to treat mphetamine intoxication.

The prolonged release of mixed amphetamine salts from ADDERALL XR ${ }^{\mathrm{TM}}$ should be considered when treating with overdose.

Dispense in a tight, light-resistant container as defined in the USP.
Store at $25^{\circ} \mathrm{C}\left(77^{\circ} \mathrm{F}\right)$. Excursions permitted to $15-30^{\circ} \mathrm{C}\left(59-86^{\circ} \mathrm{F}\right)$ [see USP Controlled Room Temperature] Manufactured by DSM Pharmaceuticals Inc., Greenville, North Carolina 27834. Distributed and marketed by Shire US Inc., Florence, KY 41042

For more information call 1-800-536-7878 or visit www.adderallxr.com

ADDERALL ${ }^{\oplus}$ is registered in the US Patent and Trademark Office 403957

(rev. 06/2002) 


\section{CNS SPECTRUMS}

The International Journal of Neuropsychiatric Medicine

EDITOR

Jack M. Gorman, MD

Mt. Sinai School of Medicine

New York, NY

\section{ASSOCIATE EDITOR}

Eric Hollander, MD

Mt. Sinai School of Medicine

New York, NY

\section{INTERNATIONAL EDITOR}

Joseph Zohar, MD

Chaim Sheba Medical Center

Tel Hashomer, Israel

\section{ASSOCIATE INTERNATIONAL EDITORS EUROPE}

Donatella Marazziti, MD

University of Pisa

Pisa, Italy

\section{MID-ATLANTIC EDITOR}

Dan J. Stein, MB

University of Stellenbosch

Tygerberg, South Africa

\section{FAR EAST EDITOR}

Shigeto Yamawaki, MD, PhD

Hiroshima University School

of Medicine

Hiroshima, Japan

\section{CONTRIBUTING WRITERS}

Cathy Budman, MD

Richard Entsuah, PhD

Wen-Zhe Ho, MD

Jeffrey M. Jones, MD, FAAN

Robert H. Paul, PhD

\section{BOARD OF ADVISORS}

Margaret Altemus, MD

Cornell University Medical Center

New York, NY

Mitchell F. Brin, MD

Allegran, Inc.

New York, NY

Dennis S. Charney, MD

Yale University

New Haven, CT

Jeffrey L. Cummings, MD

University of California

Los Angeles, CA

Dwight L. Evans, MD

University of Pennsylvania

Philadelphia, PA

Mark George, MD

Medical University of South Carolina Charleston, SC

Lorrin M. Koran, MD

Stanford University Medical School Stanford, CA

\section{Herbert Y. Meltzer, MD}

Vanderbilt University Medical Center Nashville, TN

Stuart A. Montgomery, MD

St. Mary's Hospital Medical School London, United Kingdom

Charles B. Nemeroff, MD, PhD

Emory University School of Medicine Atlanta, GA
Humberto Nicolini, MD, PhD

Instituto Mexicano de Psiquiatria Mexico City, Mexico

Katharine Phillips, MD

Brown University

Providence, RI

Harold A. Pincus, MD

Western Psychiatric Institute \& Clinic RAND-University of Pittsburgh Health Institute, Pittsburgh, PA

Scott L. Rauch, MD

Massachusetts General Hospital Charlestown, MA

Alan Schatzberg, MD

Stanford University Medical School Stanford, CA

Norman Sussman, MD

New York University Medical School New York, NY

Michael Trimble, MD

National Hospital for Neurology and Neurosurgery

London, United Kingdom

Karen Wagner, MD, PhD

University of Texas

Galveston, Tex

Herman G.M. Westenberg, MD

University Hospital Utrecht

Utrecht, The Netherlands

Stuart Yudofsky, MD

Baylor College of Medicine Houston, TX

\section{MBL COMMUNICATIONS, INC.}

\section{CEO \& PUBLISHER}

Darren L. Brodeur

MANAGING EDITOR

Christopher Naccari

SENIOR EDITOR

Deborah Hughes

DEPUTY SENIOR EDITOR

José R. Ralat

ACQUISITIONS EDITOR

Lisa Arrington

GRAPHIC DESIGNER

Anthony J. Korsak
PRODUCTION MANAGER

Lila Moses

DESIGNER, MULTIMEDIA

Michael Mosley

CONTROLLER

John Spano

SENIOR ACCOUNT MANAGER

Robert Reed

OFFICE MANAGER

Claudette Crawford

ADMINISTRATIVE ASSISTANT

Manuel Pavón
INFORMATION TECHNOLOGY

Adam Bolt

CORPORATION COUNSEL

Kevin F. Saer, Esq.

Davis, Wright, and Tremaine

ACCOUNTANT

James Kiriakos, CPA

Pegg \& Pegg

OF COUNSEL

Lawrence Ross, Esq.

Bressler, Amery, and Ross

CNS Spectrums' editorial mission is to address relevant neuropsychiatric topics, including the prevalence of comorbid diseases among patients, and reports that emphasize the profound diagnostic and physiologic connections made within the neurologic and psychiatric fields. It serves as a resource to psychiatrists and neurologists seeking to understand and treat disturbances of cognition, emotion, and behavior as a direct consequence of centeral nervous system disease, illness, or trauma. 
COGNITIVE DECLINE AND

\section{QUALITY OF LIFE IN PATIENTS WITH HIV: WHAT IS THE BEST TREATMENT?}

\section{page 860}

"HIV has evolved into a chronic condition that is complicated by neurocognitive factors. Cognitive difficulties associated with HIV are characterized by a subcortical pattern with primary deficits in information processing speed and psychomotor speed. These deficits interfere with the ability of patients to complete important instrumental activities of daily living even in the absence of dementia. Treatment of HIV improves neurocognitive functioning, but the regimens are complex and adherence is critical. Cognitive factors can negatively impact treatment adherence, which in turn results in poorer immunological, cognitive, and psychiatric outcome. This cycle emphasizes the important interrelationships between symptom expression and treatment outcome in patients with HIV. The nature of these relationships will change with further developments in treatment regimens such as once-daily dosing. Less complex treatment approaches should improve health outcome as well as provide additional opportunities to further understand the impact of HIV on brain function."

\section{SUBSTANCE P SPREADS HIV \\ page 867}

"Neuropeptides, such as SP, may play a central role in stressed HIV-infected patients by affecting immune cell functions, which may trigger further HIV disease progression and immune deficiency. In AIDS patients, abnormal neuropeptide levels may be related to severe psychological disturbances. Since SP enhances inflammatory cytokine production by immune cells, such as macrophages, and these cytokines modulate HIV infection of human immune cells that also are the targets for HIV infection, it is postulated that $\mathrm{SP}$ promotes HIV infection of these immune cells."

\section{LITERARY CHARACTERS LEAP TO LIFE IN NEUROPSYCHIATRY page 875}

"von Münchhausen's quiet life was cut short by Rudolf Eric Raspe. Raspe was a curator for Frederick II in a museum located about 50 miles south of Bodenwerder at the same time the von Münchhausen was entertaining guests with his mendacious stories. Raspe, caught embezzling from the museum, fled to England. There he anonymously published Baron Munchausen's Narrative of His Marvelous Travels and Campaigns in Russia in 1785. The book was translated into German, and made von Münchhausen an immediate celebrity. Curious tourists flocked to the von Münchhausen's estate and harassed the old man.

When von Münchhausen sued Raspe for damages, he lost the case because the title of the book had only one " $h$ " instead of two and there was no author listed. von Münchhausen became even more depressed and withdrawn in 1790 , when his wife died. He sought solace, at 74 years of age, by marrying 17-year-old Bernahardine von Brunn in 1794. Soon after, the young lady gave birth to an illegitimate daughter. von Münchhausen eventually divorced her. The proceedings involved alimony that kept von Münchhausen unhappy until he died in 1797."

\section{TICS, OBSESSIVENESS, COMPULSIONS, AND BEHCGET'S SYNDROME PRESENTED IN ONE PATIENT \\ page 878}

"During immunosuppressive therapy for presumed reexacerbation of NBS, AC experienced an explosive onset of severe OCS, including contamination fears that he would become ill from certain foods, such as red meat and pork, accompanied by compulsive hand-washing, up to 20 times daily until the skin on his hands was severely abraded, compulsions that required him check the stove and sink faucet, and to arrange/rearrange piles of papers on his desk for hours. These symptoms were accompanied by nearly constant repetitive involuntary eye-blinking, grimacing, headshaking, shoulder-shrugging, and complex vocalizations (eg, barking, echolalia)."

\section{ARE SELECTIVE SEROTONIN REUPTAKE INHIBITORS MORE EFFECTIVE THAN} VENLAFAXINE?

\section{page 882}

"Venlafaxine was consistently superior to SSRIs and placebo in every category observed, with roughly twice the benefit over placebo and 1.5 times the benefit over SSRIs. In this figure, the $\alpha$-values represent a weighted proportion of patients obtaining remission with mild AEs (category II) to patients obtaining pure remission (category I). As the $\alpha$-value decreases, the drug benefit increases and as the $\alpha$-value increases, drug benefit decreases (the more weight attributed to AEs, the greater potential negative impact on overall efficacy). So, this graphic depicts how the efficacy obtained by venlafaxine, even when associated mild AEs are considered, still has a higher relative gain over the efficacy obtained by SSRIs, when their associated AEs are considered." Cis 
BRAEF SUMMARY. See package insert for full prescribing information. CONTRAINDICATIONS: Hypersensitivity to venlafaxine hydrochloride or to any excipients in the formulation. Concomitant use in patients taking monoamine oxidase inhibitors (MAOIs) is contrandicated. WARNM NGS: Potental for Interaction with Monoamine Oxidase
Inhibitions - Adverse reactions, some serious, have been reported in patients who were recenty discontinued from an MAOI and started on venlafaxine, or who recently had venlafaxine therapy discontinued prior to initiation of an MAOL. These reactions included tremor, myoclonus, diaphoresis, nausea, vomiting, flushing, dizziness, hyperthermia with features resembling neuroleptic malignant syndrome, seizures, and death. it is recormmended that Ethexor XR not be used in combination whith an MAOA, or within at least 14 days of discontinuing treatment with an MAOLI Based on the haff-lifie of venlafaxine, at tieast 7 days should be allowed after stopping venlataxine before starting an MADI. Sustained Hypertension-Venlafaxine is associated with that sustained hypertension was dose related. It is recommended that patients receiving Effexor XR have regular monitoring of BP. For patients who experience a sustained increase in BP either cose reduction or discontinuation montoring of BP. For patients who expenence a sustained increase in BP either dose reduction or discontinuation should be considered. PreCAumions: General - Insomnia and Nervousness: Treatment-emergent insomia and
nervousness have been reported. Insomnia and nervousness each led to drug discontinuation in $0.9 \%$ of the patients nervousness have been reported. Insomnia and nervousness each led to drug discontinuation in $0.9 \%$ of the patients
in Phase 3 depression studies. In Phase 3 Generalized Anxiety Disorder (GAD) trials, insomnia and nervousness led to drug discontinuation in $3 \%$ and $2 \%$, respectively, of patients. Changes in Appetitite/Weight: Treatment-emergent anorexia has been reported. A loss of $5 \%$ or more of body weight occurred in $7 \%$ of patients in placebo-controlled
depression trias. A loss of $7 \%$ or more of body weight occurred in $3 \%$ of patients in placebo-controlled GAD trials. The safety and efficacy of venlataxine therapy in combination with weight loss agents, induding phentermine, have not been established. Caadministration of Effexor XR and weight loss agents is not recommented. Effexor XR is not indicated for weight loss alone or in combination with other products. Activation of Mania/Hypomania: Mania or hypomania has occurred during short-term depression studies. Eftexox XX should be used cautiously in patients with secretion (SIADH) may occur with venlataxine. This should be taken into consideration in patients who are, for example, volume-depleted, elderry, or taking diuretics. Mydriasis: Mydriasis has been reported; therefore patients with raised intraocular pressure or at risk of acute narrow-angle glaucoma should be monitored. Seizures: In all premarketing intraocular pressure or at risk of acute narow-angle glaucoma should be monitored. Seizures: In all premarketing
depression trials with Effexor, seizures were reported in $0.3 \%$ of venlafaxine-treated patients. Use Effexor XR cautiously depression trals with Effexor, seizures were reported in $0.3 \%$ of venlafaxine-treated patients. Use Effexor XR Cautiously
in patients with a history of seizures. Discontinue in any patient who develops seizures. Abnormal Bleeding: There have been reports of abnormal bleeding (most commonly ecchymosis. Suicide: The possibility of a suicide attempt
is inherent in depression and may persist until significant remission occurs. Closely supervise high-risk patients is inherent in depression and may persist until significant remission occurs. Closely supervise high-risk patients
during intial ding therapy. Prescriptions for Effexor XR should be written for the smallest quantity of capsules consistent with good patient management to reduce the risk of overdose. The same precautions should be observed when treating patients with GAD. Use in Pettonts With Concomitam IIness: Use Effexor XR cautiously in patients with diseases or conditions that could affect hemodynamic responses or metabolism. Venlafaxine has not been evaluated in patients with recent history of MI or unstable heart disease. In short-term depression studies electrocardiographic changes in
corrected $0 T$ interval (OTC) showed a mean increase of $4.7 \mathrm{msec}$, and the mean change from baseline heart rate was 4 beats per minute. In GAD studies, mean changes in QTC did not differ significantly from placebo and the mean change from baseline heart rate was 3 beats per minute. In a fexible-dose study with immediate release Effexor (mean dose $>300 \mathrm{mg} /$ dayl, patients had a mean increase in heart rate of 8.5 beats per minute. Caution should be exercised in patients whose underlying medical conditions might be compromised by increases in heart rate (e.g.).
patients with hyperthyroidism, heart failure, or recent $M$ I). In patients with renal impairment or cirrthosis of the liver, the patients with hyperthyroidism, heart failure, or recent $M$ M). In patients with renal impairment or cirrthosis of the liver, the
diearances of venthafaxine and its active metabolitites were decreased, thus prolonging the elimination half--lives. A lower clearances of venthafaxine and its active metabolites were decreased, thus prolonging the elimination haf-Ives. A lower
dose may be necessary; use with caution in such patients. Information for Patients-Caution patients about operating hazardous machinery, including automobiles, until they are reasonably sure that venlafaxine does not
adversely affect their abilities. Tell patients to avoid alcohol while taking Effexor $X R$ and to notity their physician 1 if adversely affect their abilities. Tell patients to avoid alcohol while taking Effexor XR and to notity their physician 1) if
they become pregnant or intend to become pregnant during therapy, or if they are nursing; 2) about other prescription or ver-the-counter drugs, including herbal preparations, they are taking or plan to take; 3) if they develop a rash, hives, or related allergic phenomena. Laboratory Tests- There are no specific laboratory tests recommended. Drug Interactions-Alcohol: A single dose of ethanol had no
0-desmethylvenlataxine (ODV When venlafaxine was administered and venlafaxine did not exaggerate the psychomotor and psychometric effects induced by ethanol. cimetidine: Use with caution when administering venlafaxine with cimetidine to
cation caution when administering venlafaxine with cimetidine to
patients with pre-existing hypertension or hepatic dystunction, patients with pre-existing hypertension or hepatic dystunction,
and the elderly. Dlazepam: A single dose of diazepam did not appear to affect the pharmacokinetics of either venlafaxine or oDv venlafaxine did not have any effect on the phamacookinetics

of diazepam or its active metaboitte, desmethyldiazepam, or affect the psychomotor and psychornetric effects induced by diazepam. Haloperidol: Venlafaxine decreased total oral-dose clearance of haloperidol which resulted in a $70 \%$ increase in haloperidol AUC. The haloperidol $C_{\text {max }}$ increased $88 \%$ when coadministered with venlafaxine, but the haloperidol elimination haf-life was unchanged. Lithium: A single dose of lithium idid not appear to affect the pharmacokinetics of either ventafaxine or 0 DVV Venlafaxine had no effect on the pharmacokinetics of lithium. Drugs cytochrome P4502D6. Drugs inhibiting this isoenzyme have the potential to increase plasma concentrations of venlafaxine and decrease concentrations of ODV. Since the composite plasma levels of venlataxine and ODV are essentially unchanged in CYP2D6 poor metabolizers, no dosage adjustment is required when venlafaxine coadministered with a CYP2D6 inhibitor. The concomitant use of venlafaxine with a drug treatment(s) that potentially coadministered with a CYP2D6 inhibitor. The concomitant use of venlataxine with a drug treatment(s) that potentially
inhibits both $C Y P 2 D 6$ and $C Y P 3 A 4$, the primary metabolizing enzymes for venlafaxine, has not been studied. Caution inhibitis both CYP2D6 and CYP3A4, the primary metabolizing enzymes tor venlafaxine, has not been studied. Caution
is advised should a patient's therapy include venlafaxine and any agent(s) that produce simultaneous inhibition of these

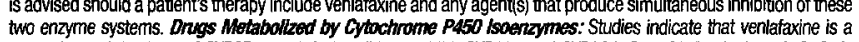
relatively weak inhibitor of CYP2D6. Venlafaxine did not inhibit CYP1 A2 and CYP3A4, CYP2C9 (in vitro), or CYP2C19,
Imipramine: Venlafaxine did not affect the pharmacokinetics of imipramine and 2-0H-imipramine. However,

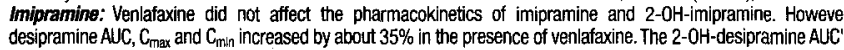
increased by 2.5-4.5 fold. Imipramine did not affect the pharmacokinetics of venlafaxine and $00 \mathrm{~V}$. Risperidone: Venlafaxine slighty inhibited the CYP2D6-mediated metabolism of risperidone to th active metabolite, 9-hydroxyrisperidonte, resulting in an approximate $32 \%$ increase in risperidone AUC. Venlafaxine coadministration did no

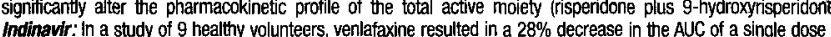
indinavir and a $36 \%$ decrease in indinavir $C_{\text {maxx }}$. Indinavir did not affect the pharmacokinetics of venlafaxine and $0 D \mathrm{~V}$. MAOls: See "Contraindications" and "Wamings." CNS-Active Drugs: Caution is advised it the concomitant adminisMAOls: See "Contraindications" and "Wamings." CuS-Active Drugs: Caution is advised if the concomitant adminis-
tration of venlafaxine and CNS-active drugs is required. Carcinogenesis, Mutagenesis, Impairment of fertilitytration of venlafaxine and CNS-active drugs is required. Carcinogenesis, Mutagenesis, Impairment of Fertility-
Carcinagenesis: There was no increase in tumors in mite and rats given up to 1.7 times the maximum Carcinagenesis: There was no increase in tumors in mite and rats given up to 1.7 times the maximum
recommended human dose (MFHD) on a mg/m $\mathrm{m}^{2}$ basis. Mutagenesis: Venlataxine and $0 \mathrm{DV}$ were not mutagenic in recommended human dose (MFHD) on a mg/m² basis. Mutagenesis: Venlataxine and ODV were not mutagenic in
the Ames reverse mutation assay in Salmonella bacteria or the Chinese hamster ovary/HGPRT mammalian cell forward gene mutation assay. Venlafaxine was not clastogenic in several assays. ODV elicited a clastogenic response
in the in vivo chromosomal aberration assay in rat bone marrow. Impaiment of Fertility: No effects on reproduction in the in vivo chromosomal aberration assay in rat bone marrow. Impaimment of Fertility: No effects on reproduction
of fertitity in rats were noted at oral doses of up to 2 times the MRHD on a $\mathrm{mg} / \mathrm{m}^{2}$ basis. Pregnancy- Teratogenic or fertility in rats were noted at oral doses of up to 2 times the MRHD on a mg/ $\mathrm{m}^{2}$ basis. Pregnancy-Teratogenic
Effects-Pregnancy Catogory $C$. Reproduction studies in rats given 2.5 times, and rabbits given 4 times the MRHD ( $\mathrm{mg} / \mathrm{m}^{2}$ basis) revealed no malformations in offspring. However, in rats given 2.5 times the MRHD, there was a
decrease in pup weight an increase in stillbom pups, and an increase in pup deaths during the first 5 days of lactation when dosing becan during pregnancy and continued until weaning. There are no adequate and well-controlled studies in pregnant women; use Effexor XR during pregnancy only if clearly needed. Nonteratogenic Effects. If venlafaxine is used until or shortly before birth, discontinuation effects in the newborn should be considered. Labor, Delivern, Nursing - The effect on labor and delivery in humans is unknown. Venlafaxine and $00 V$ have been reported Delivery, Nursing - The effect on labor and delivery in humans is unknown. Venlafaxine and ODV have been reported
to be excreted in human milk. Because of the potential for serious adverse reactions in nursing infants trom Effexor XR, to be excreted in human milk. Because of the potential for serious adverse reactions in nursing infants from Effexor XR,
a decision should be made whether to discontinue nursing or to discontinue the drug, taking into account the a decision should be made whether to discontinue nursing or to discontinue the drug, taking into account the
importance of the dung to the mother. Pestiatic Use - Safety and effectiveness in pediatric patients have not been established. Gerlatric Use-Approximately $4 \%$ and $6 \%$ of Effexor XA-treated patients in placebo-controlled premar-
keting depression and GAD tials, respectively, were 65 years of age or over. No overall differences in effectiveness or satety were observed between geriatic patients and younger patients. However, greater sensitivity of some older individuals cannot be ruled out. Several cases of hyponatremia and syndrome of inappropriate antidiliretic hormone secretion (SIADH) have been reported, usually in the elderly. AOVERSE REACTIONS: Associated with
Disconthuation of Treatment-The most common events leading to discontinuation in depression and GAD tials included: nausea, anorexia, dry mouth, dizziness, insomnia, somnolence, hypertension, tiarmea, paresthesia, temor, abnormal (mostly blured) vision, abnormal (mostly delayed) jaculation, asthenia, vomiting, nervousness, and sweating
Commonly Observed Adverse Events in Controllod Clinical Trials for Depression and GAD-Body as a Whole: asthenia. Cardiovascular: vasodilatation, hypertension. Digestive: nausea, constipation, anorexia, vomiting, flatulence. Metaboic Nututional: weight loss. Nervous System: dizziness, somnolence, insomnia, dry mouth, nervousness, abnormal dreams, tremor, depression, hypertonia, paresthesia, libido decreased, agtation. Bespiratery System: pharyngitis, yawn. Skin: Sweating. Special Senses: abnormal vision. Urocenital System: abnormal ejaculation, impotence, beats/min. (See the "Sustained Hypertension" section of "Warnings.") Laborstory Changes: Effexor XR treatment for up to 12 weeks in premarketing placebo-controlled depression trials was associated with a mean final on-therapy increase in serum cholesterol concentration of approximately $1.5 \mathrm{mg} / \mathrm{dL}$. Effexor XR treatment for up to 8 weeks and up to 6 montris in premarketing placebo-controled GAD trials was associated with mean tinal on-therapy increases
in serum cholesterol concentration of approximately $1.0 \mathrm{mg} / \mathrm{dL}$ and $2.3 \mathrm{mg} / \mathrm{dL}$, respectively. Patients treated with Effexor tablets (the immediate-release form of venlataxine) for at least 3 months in placebo-controlled 12-month extension trials had a mean final on-therapy increase in total cholesterol of $9.1 \mathrm{mg} / \mathrm{dL}$. This increase was duration dependent over the 12-month study period and tended to be greater with higher doses. An increase in serum cholesterol from baseline by $>50 \mathrm{mg} / \mathrm{dL}$ and to values $>260 \mathrm{mg} / \mathrm{dL}$, at any time after baseline, has been recorded in cholesterol from baseine by $\geq 50 \mathrm{mg} / \mathrm{dL}$ and to values $>260 \mathrm{mg} / \mathrm{LL}$, at any time after baseine, has been recorded in
$8.1 \%$ of patients. ECG Changes: See the "Use in Patients with Concomitant tilnesses" section of PRECAUTIONS. Other Events Observed During the Premarketing Evaluation of Effexor and Effexor $X R-N=5079$. "Frequent" = events occurring in at least $1 / 100$ patients; "infrequent" $=1 / 100$ to $1 / 1000$ patients; " "rare" $=$ fewer than $1 / 1000$ patients. Bady as a whole - Frequent: chest pain substemal, chills, fever, neck pain; Infrequent: face edema, intentional injury, malaise, moniliasis, neck rigidity, pelvic pain, photosensitivity reaction, suicide attempt, withdrawal syndrome; Rare: appendicitis, bacteremia, carcinoma, cellullits. Gardiovascular system - Frequent migraine, postural hypotension, tachycardia; Infrequent angina pectoris, arthythmia, extrasystoles, hypotension, peripheral vascular disorder (mainly cold feet and/or cold hands). syncope, thrombophlebits; Rare: aortic aneurysm, artertis, first-degree atrioventicular block, bigeminy, bradycardia, bundle branch block, capillary fragility, cerebral ischemia, coronary artery disease, hemornhage, myocardial infarct, pallor. Digestive ssystem - Frequent enuctation, increased appetite: Infrequent: bruxism, colitis, dysphagia, tongue edema, esophagitis, gasstrits, gastroententitis, gastrointestinal ulcer, gingivitis, glossitis, ectal hemornhage, hemorthoids, melena, oral moniliasis, stomatitis, mouth ulceration; Rare: cheiltis, cholecystitis, cholelititiasis, esophageal spasms, duodenilis, hematemessis, gastrointestinal hemorntage, gum hemorntage, hepabitis,
ileitis, jaundice, intestinal obstruction, parotitis, proctitis, increased salivation, soft stools, tongue discoloration. ileitis, jaundice, intestinal obstruction, parotitis, proctitis, increased salivation, soft stools, tongue discoloration.
Endocrine system- Rare: goiter, hyperthyroidism, hypothy roidism, thyroid nodule, thyroiditis. Hemic and homphatic system - Frequent: ecchymosis; Infrequent: anemia, leukocylosis, leukopenia, lymphadenopathy, thrombocythemia, trombocytopenia; Fare: basophilia, bleeding time increased, cyanosis, ensinophilia, lymphocytosis, multipie myeloma, purpura. Metabolic and nutritional - Frequent edema, weight gain; Intrequentst alkaline phosphatase increased, dehydration, hypercholesteremia, hyperglycemia, hyperlipemia, hypokalemia, SGOT increased, SGPT increased, thirst, Rare: alcohol intolerance, bilinubinemia, BUN increased, creatinine increased, diabetes mellitis, glycosuria, gout, healing

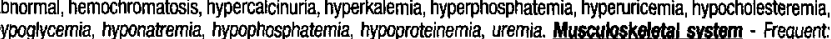
arthralgia; Infrequent arthritiss, arthrosis, bone pain, bone spurs, bursitis, leg cramps, myasthenia, tenosynovitis; Rare: pathological fracture, myopathy osteoporosis, osteosclerosis, theumatoid arthritis, tendon rupture. Nervous system Frequent: amnesia, confusion, depersonalization, emotional lability, hypesthesia, thinking abnomal, trismus, vertigo; Frequent: ammesia, contusion, depersonalization, emotional lability, hypesthesia, thinking abnormal, trismus, vertigo;
intrequent: apathy, ataxia, circumoral paresthesia, cNS stimulation, euphoria, hallucinations, hostility, hyperesthesia, intrequent: apathy, ataxia, circumoral paresthesia, CNS stimulation, euphoria, hallucinations, hostilly, hyperesthesia,

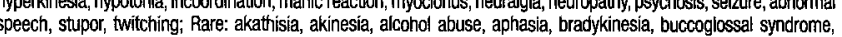
speech, stupor, twitching; Rare: akathisia, akinesia, alcohol abuse, aphasia, bradykinesia, buccoglossal syndrome,
cerebrovascular accident, loss of consciousness, delusions, dementia, dystonia, facial paralysis, abnormal gait, cerebbrovascular accident, loss of consciousness, delusions, dementia, dystonia, facial paralysis, abnormal gait,
Guillain-Bare Syndrome, hyperchlorthyoria, hypokinesia, impulse control difficulties, ibidido increased, neuritis, nystagmus, paranoid reaction, paressis, psychotic depression, reflexes decreased, reflexes increased, suiclidal ideation, torticollis. Respiratory system - Frequent: cough increased, dyspnea; Infrequent: asthma, chest congestion, epistaxis, hyperentilation, laryngismus, laryngitis, pneumonia, voice alteration; Rare: atelectasis, hemootysis, hyooventilation, hypoxia, larynx edema, pleurisy, pulmonary embolus, sleep apnea. Skin and appendagess - Frequent: rash, prurtiss; psoriasis, urticaria; Rare: enythema nodosum, exfoliative dermatitis, ilichenoid dermatitis, hair discoloration, skin discoloration, furunculosis, hirsutism, leukoderma, petechial rash, pustular rash, vesicullobullous rash, sebormea, skin atroophy, pustular rash, vesiculobullous rash, seborrmea, skin atrophy,
skin striae. Special senses - Frequent abnormality of accomskin striae. Special senses - Frequent abnormality of accom-
modation, mydriasis, taste perversion; Infrequent: cataract, conjunctivitis, comeal lesion, diplopia, dry eyes, eye pain, hyperacusis, otitis media, parosmia, photophobia, taste loss,
conjunctival edema, deafness, exophthalmos, glaucoma, retinal RXIEASE CAPSULES

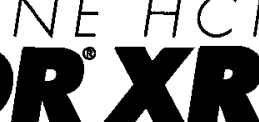

visual field defect; Rare: blepharitis, chromatopsia, conjunctival edema, deafness, exophthalmos, glaucoma, retina hemorntage, subconjunctival hemormage, kerattis, labyrinthitis, miosis, papilledema, decreased pupillary reflex, entarged prostate)," urination impaired, vaginitis"; Infrequent albuminuria, amenomea, "cystitis, hematuria, leukormea, menorthagia, nocturia, bladder pain, breast pain, polyuria, pyuria, urinary incontinence, urinary retention, urinary urgency, vaginal hemorntage,; Rare: abortion," anuria, breast discharge, breast engorgement, balanitis," breast

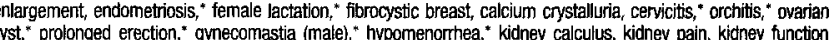
abnormal, mastitis, menopause, ${ }^{*}$ pyelonephritis, oliguria, salpingitis," urolithiasis, uterine hemorthage," uterine spasm.." ("Based on the number of men and women as appropriate). Postmarketing Reports: agranulocytosis, spasm." ("Based on the number of men and women as appropriate). Postmarketing Reports: agranulocytosis, abnormalities such as OT prolongation; cardiac arrhythmias including atrial fibrillation, supraventricular tachycardia, ventricular extrasystoles, and rare reports of ventricular fibrillation and ventricular tachycardia, including torsades de pointes; epidermal necrosis/Stevens-Johnson Syndrome, erythema multiforme, extrapyramidal symptoms (including tardive dyskinesia), hemornage (including eye and gastrointestinal bleeding), hepatic events (including GGT elevation; abnormalities of unspecified liver function tests; liver damage, necrosis, or failure; and fatty liver), involuntary movements, $1 \mathrm{DH}$ increased, neuroleptic malignant syndrome-like events (including a case of a 10-year-old who may have been taking methylphenidate, was treated and recovered), neutropenia, night sweats, pancreatitis, pancytopenia, panic, prolactin increased, pulmonary eosinophilia, renal failure, serotonin syndrome, shock-like electrical sensations (in some cases, subsequent to the discontinuation of venlafaxine or tapering of dose), and syndrome of inappropriate antidiuretic hormone secretion (usually in the elderly). There have been reports of elevated clozapine levels that were emporally associated with adverse events, including seizures, following the addition of ventafaxine. There have been eports of increases in prothrombin time, partial thromboplastin time, or INR when venlafaxine was given to patients eceiving warfarin therapy. DRUG ABUSE AND DEPENDENCE: Effexor XR is not a controlled substance. Evaluate atients carefully for history of drug abuse and observe such patients closely for signs of misuse or abuse. OVERDOSAGE: Electrocardiogram changes (e.g., prolongation of QT interval, bundle branch block, QRS prolongation), sinus and ventricular tachycardia, bradycardia, hypotension, altered level of consciousness (ranging from somnolence to employed in the management of overdosage with any antidepressant. Ensure an adequate airway, oxygenation and ventilation. Monitor cardiac rhythm and vital signs. General supportive and symptomatic measures are also recommended. Induction of emesis is not recommended. Gastric lavage with a large bore orogastric tube with appropriate airway protection, if needed, may be indicated if performed soon after ingestion or in symptomatic patients. Activated perfusion, and exchange transfusion are unlikely to be of benefit. No specific antidotes for ventafaxine are known. In managing overdosage, consider the possibility of multiple drug involvement. The physician should consider contacting poison control center for additional information on the treatment of any overdose. Telephone numbers for certified poison control centers are listed in the Physicians' Desk Reference $\mathbb{Q}^{\mathbb{Q}}$ (PDR), DOSAGE AND ADMINISTRATION: Please consult full prescribing information for detailed dosing instructions. Discontinuing Effexor $\mathrm{XR}$ - When discontinuing Effexor XR, the dose should be tapered gradually, based upon the dose, duration of therapy and the individual patient.
Discontinuation symptoms reported include agitation, anorexia, anxiety, confusion, coordination impaired, diarmea, dizziness, dry mouth, dysphoric mood, fasciculation, fatigue, headaches, hypomania, insomnia, nausea, nervousness nightmares, sensory disturbances (including shock-like electrical sensations), somnolence, sweating, tremor, vertigo and vomiting. Switching Patients To or From a Monoamine Oxidase Inhibitor-At least 14 days should elapse between discontinuation of an MAOI and initiation of therapy with Effexor XR. In addition, at least 7 days should be
allowed after stopping Effexor XR before starting an MAOI (see "Contraindications" and "Wamings"). This brief summary is based on the circular Cl $7509-4$, revised April 11,2002. 


\section{Something}

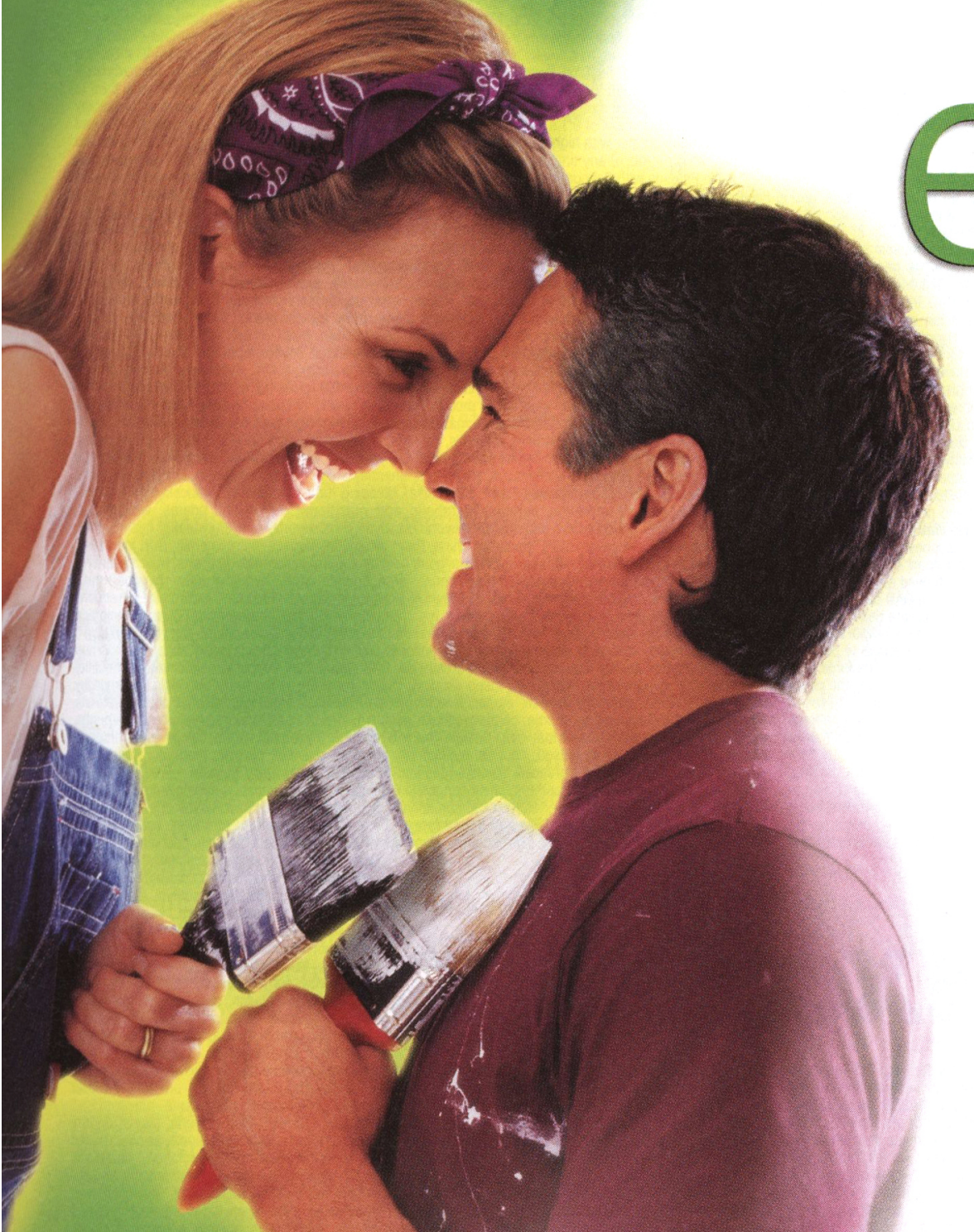

EFFEXOR XR is contraindicated in patients taking monoamine oxidase inhibitors (MAOIs). EFFEXOR XR should not be used in combination with an MAOI or within at least 14 days of discontinuing treatment with an MAOI; at least 7 days should be allowed after stopping EFFEXOR XR before starting an MAOI.

The most common adverse events reported in EFFEXOR XR placebocontrolled depression trials (incidence $\geq 10 \%$ and $\geq 2 \times$ that of placebo) were nausea, dizziness, somnolence, abnormal ejaculation, sweating, dry mouth, and nervousness; and in GAD trials were nausea, dry mouth, insomnia, abnormal ejaculation, anorexia, constipation, nervousness, and sweating. Treatment with venlafaxine is associated with sustained increases in blood pressure (BP) in some patients. Three percent of EFFEXOR XR patients in depression studies (doses of 75 to $375 \mathrm{mg} /$ day) and $0.4 \%$ in GAD studies (doses of 75 to $225 \mathrm{mg} /$ day) had sustained BP elevations. Less than $1 \%$ discontinued treatment because of elevated BP. Regular BP monitoring is recommended.

Patients should not be abruptly discontinued from antidepressant medication, including EFFEXOR XR. See the Dosage and Administration section of the Prescribing Information.

References: 1. Thase ME, Entsuah AR, Rudolph RL. Remission rates during treatment with venlafaxine or selective serotonin reuptake inhibitors. Br J Psychiatry. 2001:178:234-241. 2. Kupfer DJ. Long-term treatment of depression. IClin Psychiatty. 1991:52(5, suppl):28-34. Please see brief summary of Prescribing Information on adjacent page.

Visit us at www.EFFEXORXR.com

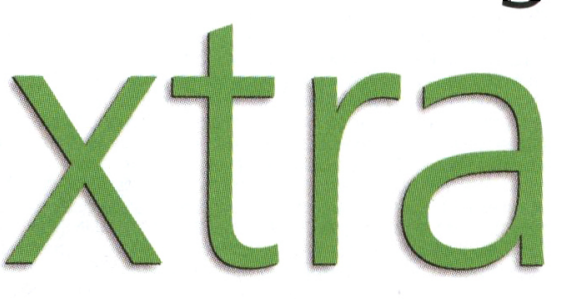

...1/3 more patients got their life back

In a pooled analysis of over 2,000 patients, against leading SSRIS (fluoxetine, paroxetine, fluvoxamine),

EFFEXOR XR/EFFEXOR offered something extraremission* of depression in $1 / 3$ more patients.'

Remission of symptoms is a first step on the road to recovery. ${ }^{2}$

* Remission is defined as minimal or no symptoms (HAM-D $\leq 7$ ). ${ }^{1}$

Indicated for Depression and

Generalized Anxiety Disorder

\section{ONCE-DAILY}

VENLAFAXINE HCI EFFEXOR XR 


\section{Table of Contents}

Feature Articles

\section{REVIEW}

860 Neurocognitive Manifestations of Human Immunodeficiency Virus

By Robert H. Paul, PhD, Ronald A. Cohen, PhD, and Robert A. Stern, PhD

\section{REVIEW}

867 Substance P and Human Immunodeficiency Virus Infection: Psychoneuroimmunology

By Wen-Zhe Ho, MD, Dwight L. Evans, MD, and Steven D. Douglas, MD

\section{REVIEW}

875 Literary Factitious Epilepsy Syndromes

By Jeffery $M$. Jones, MD, FAAN

\section{CASE STUDY}

878 An Unusual Case of Motor and Vocal Tics With Obsessive-Compulsive Symptoms in a Young Adult With Behçet's Syndrome By Cathy Budman, MD, and Adnan Sarcevic, MD

\section{ORIGINAL RESEARCH}

882 Global Benefit-risk Evaluation of Antidepressant Action: Comparison of Pooled Data for Venlafaxine, SSRIs, and Placebo By A. Richard Entsuah, PhD, and Bo Goab, PhD

\section{$\overline{\text { CNS SPECTRUMS }}^{\circ}$}

The International Journal of

Neuropsychiatric Medicine

Volume $7 \cdot$ Number 12 December 2002

CNS Spectrums is an Index Medicus journal and is available on MEDLINE. It is also indexed by DIALOG, EMBASE/Excerpta Medica, Lexis-Nexis, OVID, and SilverPlatter. CNS Spectrums is the official journal of the International Neuropsychiatric Association with members in 30 countries.

\section{CNS Spectrums}

(ISSN 1092-8529)

is published monthly by MBL Communications, Inc. 333 Hudson Street, 7th Floor New York, NY 10013

One year subscription rates: domestic \$120; foreign $\$ 185$; in-training $\$ 75$. For subscriptions: Fax 212-328-0600 or visit our Web site: www.cnsspectrums.com

Postmaster:

Send address changes to CNS Spectrums

c/o PPS Medical Marketing Group 264 Passaic Avenue

Fairfield, NJ 07004-2595 


\section{$\overline{\text { CNS SPECTRUMS }}$}

The International Journal of

Neuropsychiatric Medicine

Volume 7 - Number 12 December 2002

\section{Table of Contents}

Departments/MonthIy Columns

\section{CNS DIGEST}

838 In the Journal of December 2002

Cognitive Decline and Quality of Life in Patients With HIV: What is the Best Treatment?; Substance P Spreads HIV; Literary Characters Leap to Life in Neuropsychiatry; Tics, Obsessiveness, Compulsions, and Behçet's Syndrome Presented in One Patient; Are Selective Serotonin Reuptake Inhibitors More Effective Than Venlafaxine?

\section{CNS REPORTS}

844 News From the Fields of Neuroscience

Researchers Study New Brain-wave Treatment for Depression; Researchers Find Link Between Speech Impediments, Sleep Disorder, and Brain Damage; Association Observed Between Generalized Anxiety Disorder and Ulcers; Antiepileptic Shows Promise in Decreasing Behavioral Side Effects of Levetiracetam; 2002 CNS Spectrums Peer Reviewers

\section{THE NEUROLOGY OF BEHAVIOR}

850 William James and the Varieties of Religious Experience By Michael Trimble, MD, FRCP, FRPsych

Published 100 years ago, William James' book The Varieties of Religious Experience, remains the most revealing investigation into the psychology of religion.

\section{CONTINUING MEDICAL EDUCATION}

891 This Continuing Medical Education series gives the reader the opportunity to test his or her understanding and recall of clinical material presented in this issue. Approved for 3.0 credit hours in Category 1

\section{INDICES}

894 By subject and author

Audit Bureau of Circulations

MEMBER SINCE 2000 I

For editorial inquiries, please fax us at 212-328-0600 or e-mail us at jrr@mblcommunications.com.

For advertising inquires, please fax us at 212-328-0600 or e-mail us at $\mathbf{d l b @ m b l c o m m u n i c a t i o n s . c o m . ~}$

Opinions and views expressed by authors are their own and do not necessarily reflect the views of the publisher, MBL Communications, Inc., or the editorial advisory board. Advertisements in CNS Spectrums are accepted on the basis of adherence to ethical medical standards, but acceptance does not imply endorsement by CNS Spectrums or the publisher.

CNS Spectrums ${ }^{\circledR}$ is a registered trademark of CNS Spectrums, LLC, New York, NY.

Permission to reproduce articles in whole or part must be obtained in writing from the publisher. Copyright C2002 by MBL Communications, Inc. All rights reserved. Printed in the United States. 


\section{NOW AVAILABLE}

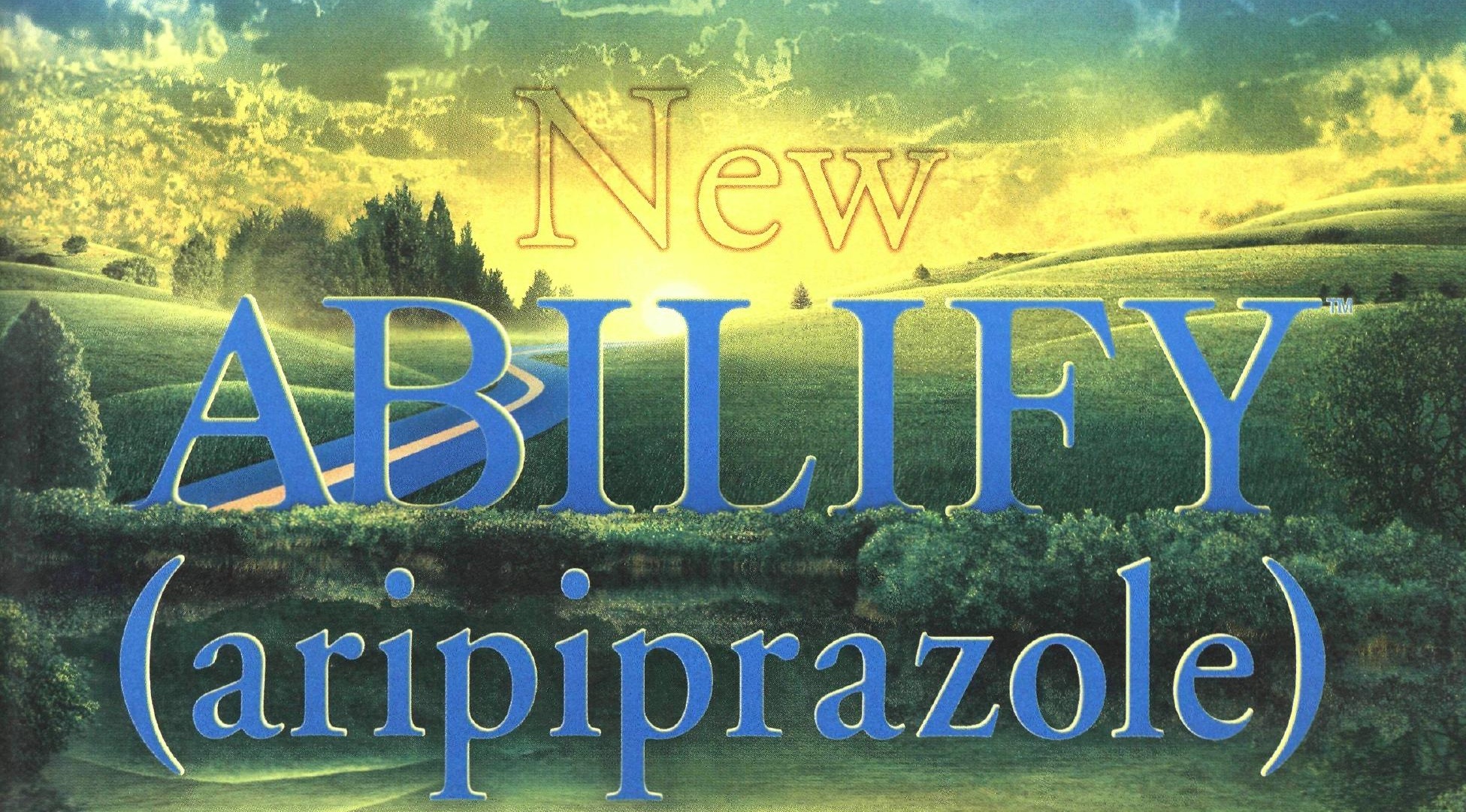

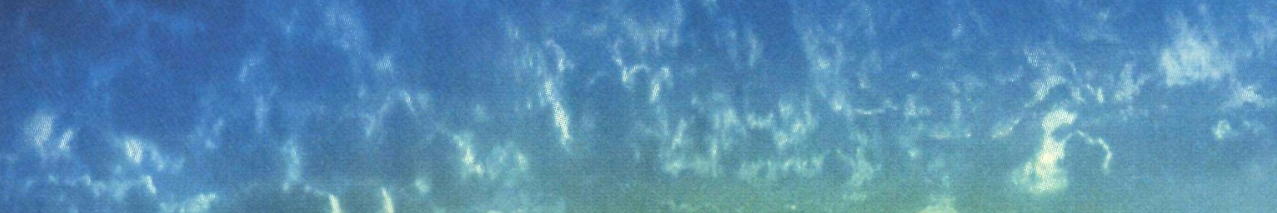

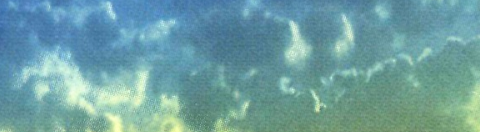

